\title{
Neutrophil and platelet-to-lymphocyte ratio predicts outcomes in patients with unresectable hepatocellular carcinoma undergoing ${ }^{131}$ I-labeled-metuximab plus transarterial chemoembolization
}

\author{
Chang Liu ${ }^{1, *}$, Guo-Jun Zeng ${ }^{2, *}$, Bang-Sheng Jia ${ }^{3}$, Jia-Yin Yang ${ }^{1}$, Li Jiang ${ }^{1}$, Hua Du ${ }^{1}$, \\ Wu-Ran Wei ${ }^{4}$, Bing-Wen Zou ${ }^{5}$ and Wu-Sheng Lu ${ }^{1}$ \\ ${ }^{1}$ Department of Liver Surgery and Liver Transplantation Center, West China Hospital, Sichuan University, Chengdu, 610041, China \\ ${ }^{2}$ Department of Vascular Surgery, West China Hospital, Sichuan University, Chengdu, 610041, China \\ ${ }^{3}$ Department of Radiology, West China Hospital, Sichuan University, Chengdu, 610041, China \\ ${ }^{4}$ Department of Urology, West China Hospital, Sichuan University, Chengdu, 610041, China \\ ${ }^{5}$ Division of Thoracic Oncology, Cancer Center, West China Hospital, Sichuan University, Chengdu, Sichuan, 610041, China \\ "These authors contributed equally to this work
}

Correspondence to: Wu-Sheng Lu, email: luwu8@126.com

Keywords: neutrophil-to-lymphocyte ratio; platelet-to-lymphocyte ratio; hepatocellular carcinoma (HCC); transarterial chemoembolization (TACE); ${ }^{131}$ I-labeled-metuxima (Licartin)

Received: May 27, 2017

Accepted: November 08, 2017

Published: January 02, 2018

Copyright: Liu et al. This is an open-access article distributed under the terms of the Creative Commons Attribution License 3.0 (CC BY

3.0), which permits unrestricted use, distribution, and reproduction in any medium, provided the original author and source are credited.

\section{ABSTRACT}

Background: The prognostic value of NLR and PLR in unresectable HCC patients undergoing ${ }^{131}$ I-labeled-metuximab plus transarterial chemoembolization has not been studied.

Materials and Methods: 184 patients with unresectable HCC were enrolled from 2009 to 2011. Data were acquired through patients' medical records and follow-up. Receiver operating curves (ROC) were used to determine the optimal cut-off levels of NLR and PLR. Kaplan-Meier univariate analysis and multivariate Cox regression analysis were used to evaluate the correlation of the NLR, PLR, and other potential prognostic factors with overall survival.

Results: The optimal cutoff levels were $\mathbf{2 . 5}$ for NLR and $\mathbf{1 0 5}$ for PLR by ROC curve analysis. Patients with NLR $\geq 2.5$ and PLR $\geq 105$ groups had significantly worse OS. The median survival time for patients with low NLR and high NLR were 19 months (2-35 months) and 10 months (2-34 months) respectively. And median survival time were 13 months (2-35 months) and 21 months (2-35 months) in the high and low PLR group respectively. Multivariate analysis showed that NLR $\geq 2.5$ (HR, 2.41; 95\% $C I, 1.26-4.13 ; P=0.034, P L R \geq 105$ (HR, 1.79; 95\% CI, 1.17-3.41; $P=0.028)$, tumor $\geq 10 \mathrm{~cm}(\mathrm{HR}, 1.81 ; 95 \% \mathrm{CI}, 1.04-2.62 ; P=0.016)$, BCLC C stage (HR, 3.12; 95\% CI, 1.72-4.98; $P=0.021)$ and albumin $35<\mathrm{g} / \mathrm{L}(\mathrm{HR}, 0.56 ; 95 \% \mathrm{CI}, 0.34-0.95 ; P=0.03)$ were independent risk factors for OS.

Conclusions: Elevated NLR and PLR were independent factors of a poor prognosis in unresectable patients undergoing ${ }^{131}$ I-labeled-metuximab plus TACE.

\section{INTRODUCTION}

Hepatocellular carcinoma (HCC) is among the most prevalent cancers worldwide, and is the third leading cause of cancer-related mortality [1]. More than $80 \%$ of HCC cases occur under the background of chronic liver disease and cirrhosis. The top three causes of $\mathrm{HCC}$ are hepatitis $\mathrm{B}$ virus (HBV), hepatitis $\mathrm{C}$ virus (HCV), and alcohol abuse [2]. The prognosis of patients with $\mathrm{HCC}$ is poor; most patients with $\mathrm{HCC}$ when admitted at hospital are diagnosed at intermediate to advanced stages of HCC, $>70 \%$ of patients, where curative treatments, such as 
hepatic resection, liver transplantation, and percutaneous radiofrequency ablation, are not feasible [3]. Transarterial chemoembolization (TACE) is a generally known treatment for intermediate to advanced-stage HCC and evidence from randomized controlled trials recognizes the efficacy of TACE in extending survival, relieving pain, and alleviating symptoms [4].

In recent years, radioimmunotherapy (RIT) has provided a new therapeutic approach for patients with HCC resulting in improved clinical outcome without severe side effects [5-7] as radiolabeled antibodies injected via the tumor feeding artery can bind and accumulated in cancer tissues, thereby destroying as much as tumor cells without normal tissue and the surrounding organs. A radioimmunological agent, ${ }^{131}$ I-labeled-metuximab (Licartin, Huasun Biotechnology Limited, Chengdu, China), in the treatment of unresectable HCC has been approved by the China State Food and Drug Administration officially. Licartin is an $\mathrm{F}\left(\mathrm{ab}^{\prime}\right) 2$ fragment of a mouse-derived HAb18/CD147 antibody, studies have demonstrated that HAb18G/ CD147 expression is particularly high in HCC tissues (75\%) but is not present in normal liver tissue, and its expression is closely related with $\mathrm{HCC}$ metastasis [8, 9]. Thus, the therapeutic effects of Licartin are primarily performed via the following mechanisms [5]: first, metuximab blocks HAb18G/CD147 antigen-induced signal transduction pathways by binding to the HAb18G/ CD147 antigen on the surface of HCC cells, as a result, reducing liver cancer metastasis and recurrence [5]. Second, ${ }^{131}$ I-metuximab exhibits a stronger inhibitory effect on the signal transduction pathway through the additional cancer-eradication power of ${ }^{131} \mathrm{I}$. Finally, ${ }^{131} \mathrm{I}$ is retained by the HCC tissues, irradiating them and causing tumor cell death, while the other tissues and organs suffer from low radiation. A previous multicenter phase IV clinical study [10] and other research [11, 12] have demonstrated satisfactory tumor targeting, suggesting high efficacy and a favorable toxicity profile of this combination therapy in treatment of intermediate to advanced $\mathrm{HCC}$.

Tumor inflammation and immunology was involved in tumor progression and metastases [13]. The calculated value of hematological components, such as neutrophilto-lymphocyte ratio (NLR) and the platelet-to-lymphocyte ratio (PLR) are correlated with poor prognosis in HCC patients treated with both curative and palliative treatments modalities, may reflect an inflammatory process elicited by tumor cells [14].

To the best of our knowledge, no studies have focused on the prognostic value of NLR and PLR in unresectable HCC patients receiving Licartin combined with TACE; the objective of this study was to evaluate the efficacy of NLR and PLR as predictors of OS for patients with intermediate to advanced $\mathrm{HCC}$ receiving Licartin plus TACE as initial therapy.

\section{MATERIALS AND METHODS}

\section{Patients}

Patients treated with Licartin combination TACE as initial therapy for unresectable HCC from January 2009 to December 2011 at the Department of Liver Surgery, West China Hospital, Sichuan University were identified within a prospectively maintained database. All patients satisfied the diagnostic criteria for $\mathrm{HCC}$ based on radiologic or histologic grounds according to the American Association for the Study of the Liver Guidelines [15]. Hepatic functional reserve was determined using the Child-Pugh classification system. Clinical variables were collected, including demographic data, complete blood count, albumin (ALB), alpha-fetoprotein (AFP), total bilirubin level (TBIL), aspartate and alanine aminotransferases, and staging of the tumor (including the number of focal hepatic lesions and maximum diameter detected during contrast-enhancement phase).

\section{Drug dosing and preoperative preparation}

A negative human anti-mouse antibody (HAMA) response to a subcutaneous injection of metuximab was confirmed and Lugol's liquid was taken orally from 3 days before the interventional procedure to 7 days after treatment (3 drops, tid for 10 days in total) to block ${ }^{131} \mathrm{I}$ uptake by the thyroid. The injection dose of Licartin was $27.75 \mathrm{MBq} / \mathrm{kg}(0.75 \mathrm{mCi} / \mathrm{kg})$ adjusted according to patient body weight [5].

\section{Procedure of TACE and Licartin intra-arterial injection}

Two different experienced interventional radiologists performed all of the interventional procedures; they had similar experiences and expertise in the management of HCC. The Seldinger method was employed to insert a 5-F transfemoral catheter into the celiac trunk and superior mesenteric artery, and arteriography was performed to ascertain the tumor site and tumor supplying branches of the hepatic artery. The appropriate dose of Licartin was administered over 5-10 min into the proper hepatic artery, followed by embolization of the tumor-feeding arteries using lipiodol (Lipiodol Ultra-Fluid; Guerbet Laboratories, Aulnay-Sous-Bois, France) and polyvinyl alcohol foam (PVA) Embolization Particles (Cook, Bloomington, IN, USA, 100-500 $\mu \mathrm{m}$ in diameter), accompanied by chemotherapy with 5-fluorouracil (800-1000 mg) and epirubicin (30-40 $\mathrm{mg}$ ) according to the body surface area. Patients were routinely injected with a maximum of $20 \mathrm{ml}$ of lipiodol to occlude the tumor-feeding artery according to individual tumor conditions. After therapy, patients were placed under a radiological quarantine and observed for 2 days inside a solitary room. 


\section{Follow-up}

Tumor responses after TACE were evaluated with contrast-enhanced computed tomography or magnetic resonance imaging and clinical symptoms and blood test results were recorded at 1,3 , and 6 months to assess response. If elevated tumor markers (AFP), diminished lipiodol, enlarged lesions, or new nodules were observed, the patients were readmitted for angiography and treatment within an interval of 1.5-3.0 months. Treatment was terminated if a patient could not tolerate the procedure because of a decline in his/her clinical status or if a patient presented with a complete response. The starting point of survival analysis was defined as the day of initial treatment. The end of follow-up was December 31, 2013, which was the time of the last follow-up, or the date of mortality. Patients who died within 60 days of the procedure were defined as periprocedural mortalities and were excluded from the post-TACE survival analysis.

\section{Statistics}

Continuous data are expressed as means and ranges, and categorical data are shown as frequencies and proportions. Categorical data are presented as frequencies and were analyzed using the Pearson $\chi 2$ test or Fisher's exact test. Receiver operating characteristic (ROC) analysis was used to determine the cut-off values of NLR and PLR. A univariate analysis was performed to assess the significance of the differences in the clinical or radiological data. A multivariate analysis was performed using the Cox regression model for variables with a significant difference in the univariate analysis. The associated 95\% confidence interval (CI) was calculated. The OS was analyzed using the KaplanMeier method. Significant differences between the groups were identified using the log-rank test. A ROC curve was also generated and the area under the curve (AUC) was calculated to evaluate the discriminatory ability. For all the other statistical tests, a $P$-value $<0.05$ was defined as significant. All statistical analyses were performed using SPSS package version 24.0 (IBM, Somers, NY, USA).

\section{RESULTS}

\section{Baseline characteristics}

184 consecutive patients were included in this study totally. The basic information of routine blood count, as well as NLR and PLR, of the patients prior to undergoing treatment are shown in Table 1. The baseline information of the patients is listed in Table 2. 153 patients were men $(83.2 \%)$ and 31 patients were women $(16.8 \%)$ among the patients. The median age of patients was 58 years (range, 18-87 years). Hepatitis B infection was the most common cause of HCC, and approximately $90.2 \%$ of the enrolled patients were positive for HBsAg. $80.5 \%$ patients had a good liver functional reserve, classified as Child-Pugh grade A. 173 cases who received Licartin procedure once, 10 cases who received Licartin twice, and one case who received three treatments session.

The prognostic ability of NLR and PLR were compared using AUC analysis, the AUC of NLR was 0.67 (95\% CI, 0.57-0.76) and the AUC of PLR was 0.61 (95\% CI, 0.51-70) (Figure 1). The optimal cut-off value was 2.5 for NLR and 105 for PLR determined by ROC analysis. The difference between the AUCs for NLR and PLR was 0.007 (95\% CI, $-0.02-0.16$ ), $P<0.001$. Therefore, HCC patients with different value of NLR were allocated to two groups, the low NLR group with NLR $<2.5(n=76)$ and high NLR group with NLR $\geq 2.5(n=108)$. Patients were also divided into two groups based on the value of PLR, the low PLR group with PLR $<105(n=91)$ and high PLR group with PLR $\geq 105(n=93)$.

The correlation between hematological inflammatory ratio and clinicopathological characteristic was analyzed (Table 2). The NLR and PLR were both related with patient age, tumor diameter, and aspartate aminotransferase (AST) $(P<0.005)$.

\section{Survival}

The 0.5, 1, and 2-year OS rates for all patients were $65.1,47.9$, and $28.5 \%$, respectively, and median OS time was 13 months (range, 2-36 months). Furthermore, Survival was stratified by NLR and PLR group. The median survival time in low NLR group was 19 months (range, 2-35 months) and 10 months (range, 2-34 months) in high NLR Group $(P=0.001$; Figure 2A). The median survival time of patients with low PLR was 21 months (range, 2-35 months), and 13 months (range, 2-35 months) in high PLR group ( $P<0.001$; Figure 2B).

\section{Prognostic factors}

All of the variables shown in Table 3 were potentially significant clinicopathologic variables of prognosis for patients with HCC. In univariate analysis (Table 3), the levels of AST $(P=0.001)$, albumin $(P<0.028)$, AFP $(P=0.005)$, tumor size $(P=0.007)$, NLR $(P=0.001)$, and PLR $(P<0.001)$ were identified as prognostic factors for OS.

Multivariate analysis (Table 3) showed that the size of the largest lesion of the tumor (hazard ratio [HR], 1.81; $95 \%$ confidence interval $[\mathrm{CI}], 1.04-2.62 ; P=0.016)$, Barcelona Clinic Liver Cancer system (BCLC) (HR, 3.12; 95\% CI, 1.72-4.98; $P=0.021$ ), NLR (HR, 2.41; 95\% CI, $1.26-4.13 ; P=0.034$ ), PLR (HR, $1.79 ; 95 \%$ CI, $1.17-$ $3.41 ; P=0.028)$ and albumin (HR, $0.56 ; 95 \% \mathrm{CI}, 0.34$ $0.95 ; P=0.03$ ) were identified as independent prognostic factors for OS. 
Table 1: Values for total white blood cells, neutrophils, lymphocytes, platelet counts, platelet-tolymphocyte ratios, and neutrophil-to-lymphocyte ratios in whole patient cohort

\begin{tabular}{llllll}
\hline Blood components & Mean & Median & Minimum & maximum & Normal value \\
\hline WBC $\left(\times 10^{9} / \mathrm{L}\right)$ & $5.86 \pm 3.14$ & 5.23 & 2.59 & 19.4 & $4.00-10.00$ \\
Neutrophil count $\left(\times 10^{9} / \mathrm{L}\right)$ & $4.00 \pm 2.68$ & 3.28 & 1.25 & 9.72 & $1.80-6.40$ \\
Lymphocyte count $\left(\times 10^{9} / \mathrm{L}\right)$ & $1.29 \pm 0.62$ & 1.17 & 0.26 & 4.21 & $1.00-3.30$ \\
Neutrophil-to-lymphocyte ratio & $3.68 \pm 3.03$ & 2.82 & 0.83 & 8.83 & 452 \\
Platelets $\left(\times 10^{9} / \mathrm{L}\right)$ & $143.77 \pm 90.64$ & 117.5 & 71 & 541.9 & $100-300$ \\
Platelet-to-lymphocyte ratio & $126.09 \pm 86.63$ & 106.76 & 19.8 & 54 \\
\hline
\end{tabular}

$\mathrm{WBC}=$ white blood cells.

\section{DISCUSSION}

Liver transplantation and partial resection are still curative treatments for HCC patients; however, for advanced HCCs staged B to C under the BCLC, treatment options such as hepatectomy, liver transplantation, and radiofrequency ablation are not suggested [16]. TACE is recommended as the most effective treatment for advanced HCC patients when compared with symptomatic treatment, because it improves survival in both cirrhotic and non-cirrhotic patients. Although the TACE protocol has been updated several times [17], the optimal strategy, best anti-tumor agents, and adjuvant treatments for TACE are still being debated [18, 19]. Besides the treatment modalities mentioned above, a few studies have expressed concerns about the use of radioimmunotherapy for

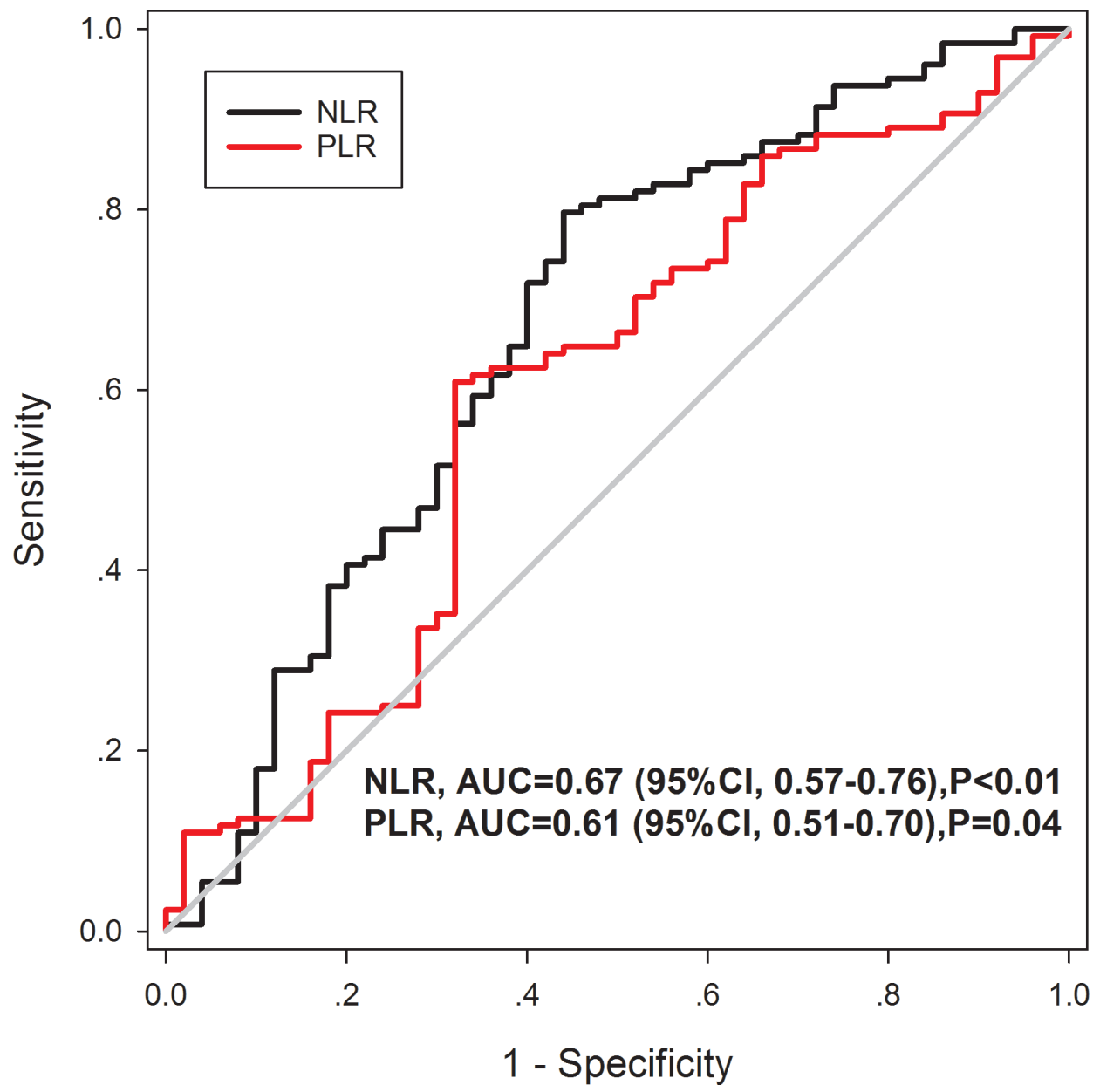

Figure 1: ROC curve of NLR and PLR predicting overall survive showing the cutoff value of 2.5 for NLR and 105 for PLR. 
Table 2: Clinicopathological correlations of patients classified by NLR and PLR

\begin{tabular}{|c|c|c|c|c|c|c|}
\hline Variables & $\begin{array}{c}\text { Low NLR } \\
(n=76)\end{array}$ & $\begin{array}{l}\text { High NLR } \\
(n=108)\end{array}$ & $p$ value & $\begin{array}{c}\text { Low PLR } \\
(n=91)\end{array}$ & $\begin{array}{c}\text { High PLR } \\
(n=93)\end{array}$ & $p$ value \\
\hline Sex & & & 0.055 & & & 0.6 \\
\hline male & 8 & 23 & & 77 & 76 & \\
\hline female & 68 & 85 & & 14 & 17 & \\
\hline Age & $60(19-76)$ & $55(18-87)$ & 0.196 & $61(35-87)$ & $55(16-82)$ & 0.003 \\
\hline BMI & $22.6(13.7-30.5)$ & $22.0(14.8-31.5)$ & 0.51 & $22.7(14.8-30.5)$ & $21.4(13.7-31.5)$ & 0.214 \\
\hline HBsAg & & & 0.22 & & & 0.345 \\
\hline present & 71 & 95 & & 84 & 82 & \\
\hline absent & 5 & 13 & & 7 & 11 & \\
\hline ChildPugh grade & & & 0.037 & & & 0.386 \\
\hline A & 67 & 82 & & 76 & 73 & \\
\hline $\mathrm{B}$ & 9 & 26 & & 15 & 20 & \\
\hline Tumor number & & & 0.505 & & & 0.142 \\
\hline Solitary & 42 & 65 & & 48 & 59 & \\
\hline Multiple & 34 & 43 & & 43 & 34 & \\
\hline $\begin{array}{l}\text { Maximum tumor } \\
\text { diameter }\end{array}$ & $5.9(0.7-14.0)$ & $8.7(1.5-19.7)$ & 0.009 & $4.6(0.7-13.1)$ & $10.3(1.8-19.7)$ & $<0.001$ \\
\hline Vascular invasion & & & 0.222 & & & 0.174 \\
\hline Present & 29 & 51 & & 35 & 45 & \\
\hline Absent & 47 & 57 & & 56 & 48 & \\
\hline BCLC Stage & & & 0.190 & & & 0.461 \\
\hline $\mathrm{B}$ & 43 & 51 & & 48 & 44 & \\
\hline $\mathrm{C}$ & 33 & 58 & & 43 & 49 & \\
\hline ALB, g/L & $38.7(26.2-105.0)$ & $38.1(17.6-67.2)$ & 0.381 & $39.2(17.6-68.8)$ & $37.5(21.1-105.0)$ & 0.239 \\
\hline TBIL, $\mu \mathrm{mol} / \mathrm{L}$ & $15.5(6.5-38.5)$ & $18.6(5.4-39.3)$ & 0.653 & $17.5(6.5-38.6)$ & $16.5(5.4-39.3)$ & 0.274 \\
\hline ALT, IU/L & $45(13-181)$ & $46(9-227)$ & 0.989 & $43(10-640)$ & $45(10-640)$ & 0.583 \\
\hline AST, IU/L & $50(8.2-348)$ & $80(16-487)$ & 0.007 & $51.5(13-321)$ & $81(8.2-487)$ & 0.004 \\
\hline PT, sec (range) & $12.2(9.6-15.9)$ & $12.5(9.8-15.7)$ & 0.23 & $12.4(9.6-15.9)$ & $12.3(9.7-15.7)$ & 0.195 \\
\hline INR (range) & $1.1(0.9-1.5)$ & 1.1(0.9-1.4) & 0.173 & $1.1(0.9-1.5)$ & 1.1(0.9-1.4) & 0.162 \\
\hline AFP, ng/mL & $90.9(1.7-1210)$ & $293.9(1.1-1210)$ & 0.377 & $78.7(1.7-1210)$ & $806(1.1-1210)$ & 0.17 \\
\hline Sessions of TACE & $2(1-9)$ & $2(1-7)$ & 0.493 & $2(1-9)$ & $1(1-7)$ & 0.148 \\
\hline
\end{tabular}

$\mathrm{BMI}=$ body mass index; NLR $=$ neutrophil-to-lymphocyte ratio, $\mathrm{WBC}=$ white blood cells, PLT $=$ platelets, ALT $=$ alanine transaminase, $\mathrm{AST}=$ aspartate transaminase, HBsAg $=$ hepatitis $\mathrm{B}$ surface antigen, $\mathrm{AFP}=\alpha$-fetoprotein, $\mathrm{TBIL}=$ total bilirubin, $\mathrm{ALB}=$ albumin, $\mathrm{PT}=$ prothrombin time; INR = international normalized ratio, $\mathrm{BCLC}=\mathrm{Barcelona} \mathrm{Clinic}$ Liver Cancer system.

treatment of HCC. About 30 year ago, Goldenberg first introduced ${ }^{131} 1$-labeled into detection and localization of diverse cancers by external photoscanning [20], and with the improvement of hybridoma technology [21], a series of new reagents specifically binding to tumor cells were developed and utilized in the world [22]. In 2006, Licartin was introduced into clinical applications and was reported to be effective in preventing tumor recurrence after orthotropic liver transplantation [23]. Ma et al. [10]. summarized and analyzed the data of Licartin plus TACE in combination therapy for unresectable hepatocellular carcinoma, they demonstrated better localization of Licartin in liver tumors than in other tissues $(P<0.01)$, the organ absorbed doses to liver was higher than to red marrow $(3.19 \pm 1.01$ Gy vs. $0.55 \pm 0.22$ Gy).

Recently, a meta-analysis [24] evaluated the efficacy and safety of TACE plus Licartin compared with TACE alone in advanced HCC patients, and their review demonstrated that patients receiving TACE plus Licartin showed significant improvements in efficacy and OS. 
Table 3: Univariate and multivariate analysis for overall survival in whole HCC patients cohort

\begin{tabular}{|c|c|c|c|c|}
\hline \multirow[b]{2}{*}{ Variables } & \multicolumn{2}{|c|}{ Univariate analysis } & \multicolumn{2}{|c|}{ Multivariate analysis } \\
\hline & Hazard ratio $(95 \% \mathrm{CI})$ & $p$ value & Hazard ratio $(95 \% \mathrm{CI})$ & $p$ value \\
\hline Age, year & $0.96(0.66-1.41)$ & 0.851 & & \\
\hline \multicolumn{5}{|l|}{$<50$} \\
\hline \multicolumn{5}{|l|}{$\geq 50$} \\
\hline Gender & $1.19(0.73-1.96)$ & 0.471 & & \\
\hline \multicolumn{5}{|l|}{ Male } \\
\hline \multicolumn{5}{|l|}{ Female } \\
\hline HBsAg & $0.79(0.43-1.43)$ & 0.432 & & \\
\hline \multicolumn{5}{|l|}{ Present } \\
\hline \multicolumn{5}{|l|}{ Absent } \\
\hline $\mathrm{ALT}, \mu / 1$ & $0.92(0.64-1.33)$ & 0.66 & & \\
\hline \multicolumn{5}{|l|}{$<40$} \\
\hline \multicolumn{5}{|l|}{$\geq 40$} \\
\hline $\mathrm{AST}, \mu / 1$ & $1.92(1.31-2.82)$ & 0.001 & & \\
\hline \multicolumn{5}{|l|}{$<55$} \\
\hline \multicolumn{5}{|l|}{$\geq 55$} \\
\hline Albumin, g/l & $0.66(0.45-0.96)$ & 0.028 & $0.56(0.34-0.95)$ & 0.03 \\
\hline \multicolumn{5}{|l|}{$<35$} \\
\hline \multicolumn{5}{|l|}{$\geq 35$} \\
\hline Total serum bilirubin, $\mu \mathrm{mol} / 1$ & $1.36(0.934-1.98)$ & 0.109 & & \\
\hline \multicolumn{5}{|l|}{$<20$} \\
\hline \multicolumn{5}{|l|}{$\geq 20$} \\
\hline $\mathrm{AFP}, \mathrm{ng} / \mathrm{ml}$ & $1.69(1.17-2.46)$ & 0.005 & & \\
\hline \multicolumn{5}{|l|}{$<400$} \\
\hline \multicolumn{5}{|l|}{$\geq 400$} \\
\hline PT, sec & $0.38(0.79-1.54)$ & 0.174 & & \\
\hline \multicolumn{5}{|l|}{$<13.5$} \\
\hline \multicolumn{5}{|l|}{$\geq 13.5$} \\
\hline Diameter of largest lesion, $\mathrm{cm}$ & $1.93(1.19-3.12)$ & 0.007 & $1.81(1.04-2.62)$ & 0.016 \\
\hline \multicolumn{5}{|l|}{$<10$} \\
\hline \multicolumn{5}{|l|}{$\geq 10$} \\
\hline Tumor number & $0.89(0.59-1.35)$ & 0.593 & & \\
\hline \multicolumn{5}{|l|}{ Solitary } \\
\hline \multicolumn{5}{|l|}{ Multiple } \\
\hline Vascular invasion & & 0.104 & & \\
\hline Absent & & & & \\
\hline Present & & & & \\
\hline Child-Pugh grade & $1.03(0.64-1.67)$ & 0.904 & & \\
\hline A & & & & \\
\hline B & & & & \\
\hline BCLC Stage & $2.12(1.66-2.71)$ & $<0.001$ & $3.12(1.72-4.98)$ & 0.021 \\
\hline $\mathrm{B}$ & & & & \\
\hline $\mathrm{C}$ & & & & \\
\hline
\end{tabular}



NLR
$1.89(1.28-2.81)$
0.001
$2.41(1.26-4.13)$
0.034
$<2.5$
$\geq 2.5$
PLR
$1.96(1.34-2.85)$
$<0.001$
$1.79(1.17-3.41)$
0.028
$<105$
$\geq 105$

Therefore, the benefits of the use of radioimmunoconjugates with TACE for treating advanced HCCs have been acknowledged.

In our center, ${ }^{131} \mathrm{I}$-labeled metuximab has been applied to advanced HCC patients since the year 2003 and some of the authors of this study took part in the initial phase I/II clinical trials [5]. A previous study from our center also emphasized that combination treatment was safe and effective [12] and the powerful combination resulted in a potentially collaborative benefit. The potential mechanisms may be explained by following two aspects. First, embolization of the tumor feeding artery can reduce blood flow to the HCC, and may enhance the efficacy of Licartin due to the prolonged retention in the tumor. Second, the antitumor drug may have a radio-sensitizing effect, which allowed Licartin to kill cancer cells by continuous radiation.

It is clarified that the utilization of ascites, physical performance status, hepatic function, serum biomarker, and tumor clinicopathological features to predict survival in patients with HCC is useful [25]. Nowadays, in clinical practice, white blood count has been used as a traditional inflammatory marker. Compared with other clinical applied inflammation-based scores, such as Glasgow prognostic score (GPS), modified GPS (mGPS), prognostic index (PI), and prognostic nutritional index (PNI), NLR and PLR are inferior markers [26]. However, with the advantage of being more universally available and less expensive, NLR and PLR are widely used and have been shown to have satisfactory abilities in predicting

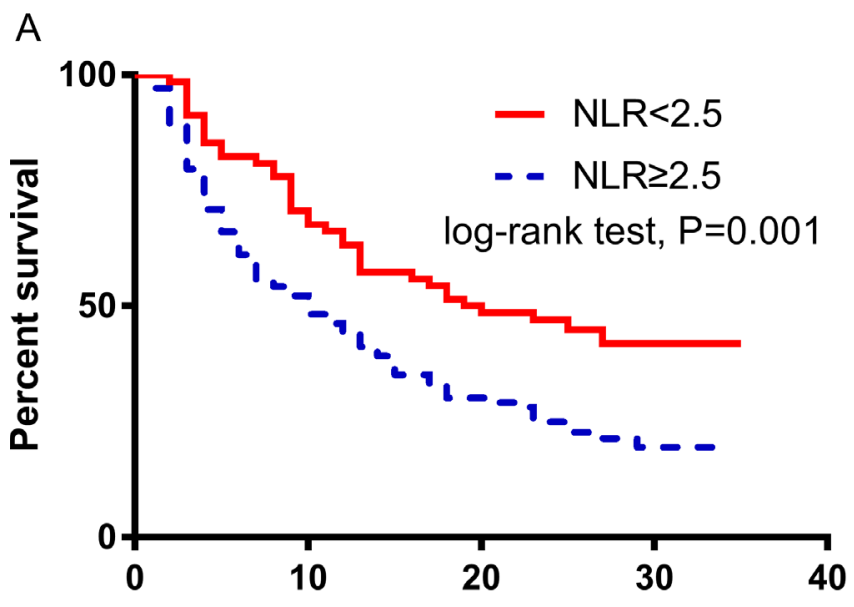

outcomes in patients with different kinds of cancers. In fact, an association between NLR and PLR and colorectal cancer, non-small cell lung cancer, breast cancer, and ovarian cancer have been reported [27-29]. It has also been shown that for patients in various stages of HCC, a high NLR and PLR are unfavorable prognostic indicators regardless of whether they undergo surgical resection, transplantation, TACE, or radiofrequency ablation (RFA).

As evaluated in multivariate analysis, ROC, and survival curves according to the cut-off value of NLR and PLR, we showed that NLR and PLR were independent prognostic factors for OS in HCC patients who underwent radioimmunoconjugate therapy combined with TACE. There are several possible explanations as follows: neutrophils can be stimulated to express various cytokines, which results in modifications to the microenvironment supportive of tumor progression and development [30]. Neagoe et al. [31]. confirmed that tumor growth and metastasis can be promoted by neutrophils. On the other hand, platelets promote immune-mediated liver injury by accumulation of virus-specific CD8p T cells at liver, which are thought to trigger the multiple genetic alterations that typify HCC [32]. Platelet-derived growth factor was confirmed to enhance tumor progression and metastasis [33]. Furthermore, platelets can facilitate tumorigenesis and angiogenesis by increasing levels of cytokine vascular endothelial growth factor, proteases and angiogenesisregulating chemokines. On the contrary, lymphocytes is important in preventing tumor growth [34]. Patients with

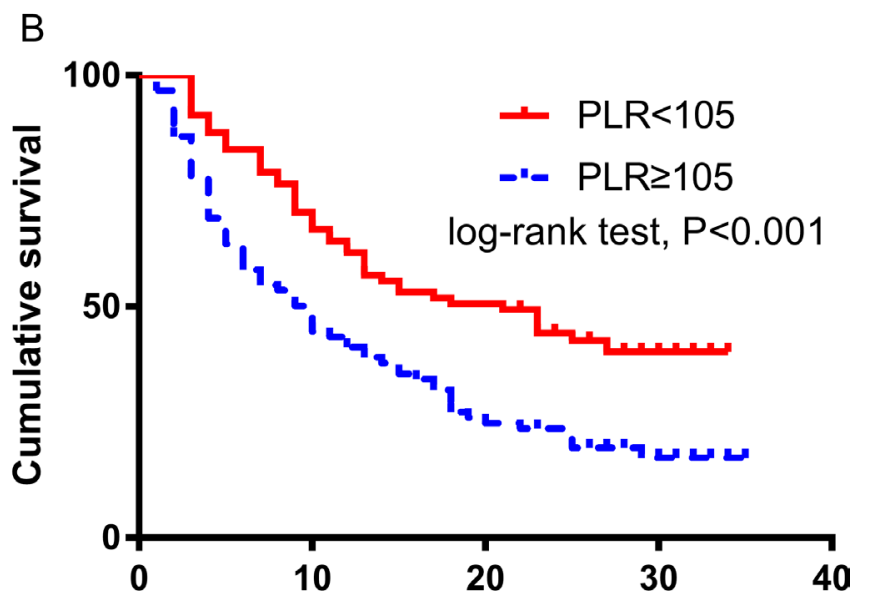

Figure 2: Kaplan-Meier curves for OS in patients with HCC who were treated with ${ }^{131}$ I-Labeled-Metuximab Plus TransarterialTACE were stratified by NLR and PLR. (A) NLR; (B) PLR. 
an elevated PLR might have a relative low lymphocyte count, which might result in suppression of antitumor immunity via a decrease in regulatory T cells [35].

Pinato et al. [36] first illustrated that HCC patients with a persistently increased NLR $(>5)$ have a worse outcome after TACE. McNally et al. [37]. also examined the value and changing trends of NLR pre- and postTACE. Their study revealed that perioperative changes of NLR are related with outcomes in patients with unresectable HCC undergoing TACE. The same goes for the PLR; some researchers have suggested that the combination of NLR and PLR could predict the prognosis of patients with HCC treated with liver resection [38].

The chief reason why the post-treatment blood parameters were not included in our study is that we noticed there is an increased incidence of marrow suppression after combined therapy, such as leucopenia and thrombocytopenia. The adverse effect (AE) rates that occurred in our center were consistent with Ma et al. [10]. They showed that grade 3 AEs thrombocytopenia $(4.8 \%$ vs. $0.6 \%)$ in patients undergoing combined therapy compared with TACE alone, and both leucopenia and thrombocytopenia, increased markedly in the treatment group $(P<0.001, P=0.013)$. The leucopenia appeared mainly at day 20 after procedure and thrombocytopenia occurred at days 3-7 after procedures and decreased gradually to normal level at month 2 . Therefore, the posttreatment NLR and PLR data collected at these common time points could lead to misleading results and the majority of patients would receive their next session of treatment only following normalization of blood indicators.

This study had several limitations. First, this is a retrospective study conducted in a single-center, the results require external validation from other research groups. Second, only the correlation of NLR and PLR with the outcomes of patients with HCC were analyzed, whether NLR and PLR are more useful in predicting OS in patients with HCC as compared to other systemic inflammationbased prognostic factors remains to be ascertained. Finally, all patients were ethnically Chinese and the predominant etiology of liver fibrosis was HBV infection.

\section{CONCLUSIONS}

The present study illustrated that the NLR and PLR were independent prognostic factors for patients with unresectable HCC undergoing Licartin combined with TACE. The importance of NLR and PLR for assessing the OS of unresectable patients undergoing Licartin combined with TACE should be acknowledged.

\section{CONFLICTS OF INTEREST}

The authors declared that they do not have anything to disclose regarding funding or any conflicts of interest with respect to this manuscript.

\section{FUNDING}

This study was supported by grants from the National Natural Science Foundation of China (No.81400636).

\section{REFERENCES}

1. Jemal A, Bray F, Center MM, Ferlay J, Ward E, Forman D. Global cancer statistics. CA Cancer J Clin. 2011; 61:69-90.

2. El-Serag HB, Rudolph KL. Hepatocellular carcinoma: epidemiology and molecular carcinogenesis. Gastroenterology. 2007; 132:2557-2576.

3. Saraswat VA, Pandey G, Shetty S. Treatment algorithms for managing hepatocellular carcinoma. J Clin Exp Hepatol. 2014 (Suppl 3); 4:S80-89.

4. Llovet JM, Bruix J. Systematic review of randomized trials for unresectable hepatocellular carcinoma: Chemoembolization improves survival. Hepatology. 2003; 37:429-442.

5. Chen ZN, Mi L, Xu J, Song F, Zhang Q, Zhang Z, Xing JL, Bian HJ, Jiang JL, Wang XH, Shang P, Qian AR, Zhang $\mathrm{SH}$, et al. Targeting radioimmunotherapy of hepatocellular carcinoma with iodine $\left({ }^{131} \mathrm{I}\right)$ metuximab injection: clinical phase I/II trials. Int J Radiat Oncol Biol Phys. 2006; 65:435-444.

6. Steiner M, Neri D. Antibody-radionuclide conjugates for cancer therapy: historical considerations and new trends. Clin Cancer Res. 2011; 17:6406-6416.

7. Zeng ZC, Tang ZY, Yang BH, Liu KD, Wu ZQ, Fan J, Qin LX, Sun HC, Zhou J, Jiang GL. Comparison between radioimmunotherapy and external beam radiation therapy for patients with hepatocellular carcinoma. Eur J Nucl Med Mol Imaging. 2002; 29:1657-1668.

8. Ke X, Li L, Dong HL, Chen ZN. Acquisition of anoikis resistance through CD147 upregulation: A new mechanism underlying metastasis of hepatocellular carcinoma cells. Oncol Lett. 2012; 3:1249-1254.

9. Zhao P, Zhang W, Wang SJ, Yu XL, Tang J, Huang W, Li Y, Cui HY, Guo YS, Tavernier J, Zhang SH, Jiang JL, Chen ZN. HAb18G/CD147 promotes cell motility by regulating annexin II-activated RhoA, Rac1 signaling pathways in hepatocellular carcinoma cells. Hepatology. 2011; 54:2012-2024.

10. Ma J, Wang JH. ${ }^{131} \mathrm{I}$-Labeled-Metuximab Plus Transarterial Chemoembolization in Combination Therapy for Unresectable Hepatocellular Carcinoma: Results from a Multicenter Phase IV Clinical Study. Asian Pac J Cancer Prev. 2015; 16:7441-7447.

11. Wu L, Yang YF, Ge NJ, Shen SQ, Liang J, Wang Y, Zhou WP, Shen F, Wu MC. Hepatic artery injection of ${ }^{131}$ I-labelled metuximab combined with chemoembolization for intermediate hepatocellular carcinoma: a prospective nonrandomized study. Eur J Nucl Med Mol Imaging. 2012; 39:1306-1315.

12. He Q, Lu WS, Liu Y, Guan YS, Kuang AR. ${ }^{131}$ I-labeled metuximab combined with chemoembolization for 
unresectable hepatocellular carcinoma. World J Gastroenterol. 2013; 19:9104-9110.

13. Colotta F, Allavena P, Sica A, Garlanda C, Mantovani A. Cancer-related inflammation, the seventh hallmark of cancer: links to genetic instability. Carcinogenesis. 2009; 30:1073-1081.

14. Huang ZL, Luo J, Chen MS, Li JQ, Shi M. Blood neutrophil-to-lymphocyte ratio predicts survival in patients with unresectable hepatocellular carcinoma undergoing transarterial chemoembolization. J Vasc Interv Radiol. 2011; 22:702-709.

15. Bruix J, Sherman M. Management of hepatocellular carcinoma. Hepatology. 2005; 42:1208-1236.

16. Maluccio M, Covey A. Recent progress in understanding, diagnosing, and treating hepatocellular carcinoma. CA Cancer J Clin. 2012; 62:394-399.

17. Llovet JM. Updated treatment approach to hepatocellular carcinoma. J Gastroenterol. 2005; 40:225-235.

18. Kamran AU, Liu Y, Li FE, Liu S, Wu JL, Zhang YW. Transcatheter Arterial Chemoembolization With Gelatin Sponge Microparticles Treated for BCLC Stage B Hepatocellular Carcinoma: A Single Center Retrospective Study. Medicine (Baltimore). 2015; 94:e2154.

19. Imai Y, Chikayama T, Nakazawa M, Watanabe K, Ando S, Mizuno Y, Yoshino K, Sugawara K, Hamaoka K, Fujimori K, Inao M, Nakayama N, Oka M, et al. Usefulness of miriplatin as an anticancer agent for transcatheter arterial chemoembolization in patients with unresectable hepatocellular carcinoma. J Gastroenterol. 2012; 47:179-186.

20. Goldenberg DM, DeLand F, Kim E, Bennett S, Primus FJ, van Nagell JJ, Estes N, DeSimone P, Rayburn P. Use of radiolabeled antibodies to carcinoembryonic antigen for the detection and localization of diverse cancers by external photoscanning. N Engl J Med. 1978; 298:1384-1386.

21. Kohler G, Milstein C. Continuous cultures of fused cells secreting antibody of predefined specificity. Nature. 1975; 256:495-497.

22. Koprowski H, Steplewski Z, Herlyn D, Herlyn M. Study of antibodies against human melanoma produced by somatic cell hybrids. Proc Natl Acad Sci USA. 1978; 75:3405-3409.

23. Xu J, Shen ZY, Chen XG, Zhang Q, Bian HJ, Zhu P, Xu HY, Song F, Yang XM, Mi L, Zhao QC, Tian R, Feng Q, et al. A randomized controlled trial of Licartin for preventing hepatoma recurrence after liver transplantation. Hepatology. 2007; 45:269-276.

24. Zhu ZX, Liao MH, Wang XX, Huang JW. Transcatheter Arterial Chemoembolization Plus ${ }^{131}$ I-Labelled Metuximab versus Transcatheter Arterial Chemoembolization Alone in Intermediate/Advanced Stage Hepatocellular Carcinoma: A Systematic Review and Meta-Analysis. Korean J Radiol. 2016; 17:882-892.

25. Bruix J, Llovet JM. Prognostic prediction and treatment strategy in hepatocellular carcinoma. Hepatology. 2002; 35:519-524.
26. Proctor MJ, Morrison DS, Talwar D, Balmer SM, Fletcher CD, O'Reilly DS, Foulis AK, Horgan PG, McMillan DC. A comparison of inflammation-based prognostic scores in patients with cancer. A Glasgow Inflammation Outcome Study. Eur J Cancer. 2011; 47:2633-2641.

27. Unal D, Eroglu C, Kurtul N, Oguz A, Tasdemir A. Are neutrophil/lymphocyte and platelet/lymphocyte rates in patients with non-small cell lung cancer associated with treatment response and prognosis? Asian Pac J Cancer Prev. 2013; 14:5237-5242.

28. Takeuchi H, Kawanaka H, Fukuyama S, Kubo N, Hiroshige S, Yano T. Comparison of the prognostic values of preoperative inflammation-based parameters in patients with breast cancer. Plos One. 2017; 12:e177137.

29. Pedrazzani C, Mantovani G, Fernandes E, Bagante F, Luca SG, Surci N, Campagnaro T, Ruzzenente A, Danese E, Lippi G, Guglielmi A. Assessment of neutrophil-tolymphocyte ratio, platelet-to-lymphocyte ratio and platelet count as predictors of long-term outcome after R0 resection for colorectal cancer. Sci Rep. 2017; 7:1494.

30. Zerbini A, Pilli M, Laccabue D, Pelosi G, Molinari A, Negri E, Cerioni S, Fagnoni F, Soliani P, Ferrari C, Missale G. Radiofrequency thermal ablation for hepatocellular carcinoma stimulates autologous NK-cell response. Gastroenterology. 2010; 138:1931-1942.

31. Neagoe PE, Brkovic A, Hajjar F, Sirois MG. Expression and release of angiopoietin-1 from human neutrophils: intracellular mechanisms. Growth Factors. 2009; 27:335-344.

32. Guidotti LG, Chisari FV. Immunobiology and pathogenesis of viral hepatitis. Annu Rev Pathol. 2006; 1:23-61.

33. Sierko E, Wojtukiewicz MZ. Platelets and angiogenesis in malignancy. Semin Thromb Hemost. 2004; 30:95-108.

34. Dunn GP, Old LJ, Schreiber RD. The immunobiology of cancer immunosurveillance and immunoediting. Immunity. 2004; 21:137-148.

35. Ding PR, An X, Zhang RX, Fang YJ, Li LR, Chen G, Wu XJ, Lu ZH, Lin JZ, Kong LH, Wan DS, Pan ZZ. Elevated preoperative neutrophil to lymphocyte ratio predicts risk of recurrence following curative resection for stage IIA colon cancer. Int J Colorectal Dis. 2010; 25:1427-1433.

36. Pinato DJ, Sharma R. An inflammation-based prognostic index predicts survival advantage after transarterial chemoembolization in hepatocellular carcinoma. Transl Res. 2012; 160:146-152.

37. McNally ME, Martinez A, Khabiri H, Guy G, Michaels AJ, Hanje J, Kirkpatrick R, Bloomston M, Schmidt CR. Inflammatory markers are associated with outcome in patients with unresectable hepatocellular carcinoma undergoing transarterial chemoembolization. Ann Surg Oncol. 2013; 20:923-928.

38. Li C, Wen TF, Yan LN, Li B, Wang WT, Yang JY, Xu MQ. Postoperative neutrophil-to-lymphocyte ratio plus plateletto-lymphocyte ratio predicts the outcomes of hepatocellular carcinoma. J Surg Res. 2015; 198:73-79. 